rev.relac.int.estrateg.segur.8(1):207-231,2013

\title{
ESTRUCTURAS CLIENTELARES Y PARTIDOS POLÍTICOS. APROXIMACIONES A LA CRISIS Y TRANSFORMACIÓN DE LOS SISTEMAS DE PARTIDOS EN COLOMBIA Y VENEZUELA*
}

\author{
Jorge Orlando Blanco Suárez ${ }^{* *}$
}

\section{RESUMEN}

El propósito de este documento es dar cuenta del papel que pueden desempeñar ciertas formas de clientelismo en regímenes políticos similares desde el punto de vista institucional. Se parte de una presentación general del concepto de Clientelismo para, desde una mirada amplia del mismo, juzgar el papel que éste ha desempeñado en dos casos de bipartidismo y presidencialismo: Colombia y Venezuela.

* Artículo de revisión, resultado final del seminario doctoral "Sistemas Políticos en los Países Andinos", orientado por el doctor Simón Pachano, dentro del Doctorado en Ciencias Sociales con Especialización en Estudios Andinos, de la Facultad Latinoamericana de Ciencias Sociales, con sede en Quito-Ecuador. Agradezco al doctor Pachano y a la doctora Carolina Curvale por sus valiosos comentarios y aportes para este trabajo. La realización del documento contó con el apoyo financiero de la Universidad Distrital Francisco José de Caldas y de La Facultad Latinoamericana de Ciencias Sociales, Quito-Ecuador. Agradezco los comentarios y observaciones del evaluador anónimo.

** Doctorante en Ciencias Sociales con Especialización en Estudios Andinos, Facultad Latinoamericana de Ciencias Sociales, Quito-Ecuador. Docente-Investigador de la Universidad Distrital Francisco José de Caldas, Facultad de Ciencias y Educación. Miembro del Grupo de Investigación Amauta. Pedagogías críticas y formación de sujetos. joblancos@udistrital.edu.co, jorgoblan@gmail.com 
Se propone que el clientelismo ha sido un elemento fundamental para la estabilidad del sistema político colombiano y, dadas sus formas de manifestación en Venezuela, por el contrario, se convirtió allí en uno de los elementos principales de la crisis de su sistema bipartidista.

Palabras clave: clientelismo, Partidos Políticos, Presidencialismo, Democracia.

\title{
CLIENTELIST STRUCTURES AND POLITICAL PARTIES. AN APPROACH TO THE CRISIS AND TRANSFORMATION OF THE PARTY SYSTEMS IN COLOMBIA AND VENEZUELA
}

\begin{abstract}
The purpose of this document is to comment on the role played by certain types of clientelism in political regimes, similar from an institutional point of view. The starting point is a general concept of the clientelist system, so that from a broad perspective of that concept, be able to judge the role played by this political idea in two cases of bipartisanship and presidential rule: Colombia and Venezuela. It is proposed that the clientelist system played an important role in the stability of the Colombian political system and, on the contrary, given its characteristics in the Venezuelan regime, it became one of the main elements of the crisis in its two-party system.
\end{abstract}

Keywords: Clientelism, Political parties, Presidential rule, Democracy

\section{ESTRUTURAS CLIENTELISTAS E PARTIDOS POLÍTICOS. ABORDAGENS SOBRE A CRISE E A TRANSFORMAÇÃO DOS SISTEMAS DE PARTIDOS NA COLÔMBIA E VENEZUELA}

\section{RESUMO}

O objetivo deste artigo é explicar o papel que podem desempenhar algumas formas de clientelismo em regimes políticos semelhantes desde o ponto de vista institucional. Toma-se como ponto de partida uma visão geral do conceito de Clientelismo para, a partir de uma visão ampla do mesmo, julgar o papel que desempenhou nos dois casos de bipartidarismo e presidencialismo: a Colômbia e a Venezuela. A proposta é que o clientelismo foi um elemento fundamental para a estabilidade do sistema político colombiano, e a forma como se manifestou na Venezuela, pelo contrário, se tornou um dos principais elementos da crise de seu sistema bipartidário.

Palavras chave: clientelismo, Partidos Políticos, Presidencialismo, Democracia. 


\section{INTRODUCCIÓN}

La historia de Colombia y Venezuela fue, durante un buen tiempo, la de dos países con una democracia estable y una estructura partidista que les proporcionaba estabilidad. En Venezuela, a partir del fin de la dictadura de Marcos Pérez Jiménez, en 1958, dos partidos políticos (Acción Democrática -AD- y el Comité de Organización Política Electoral Independiente - COPEI) lograron hegemonizar el espectro político. En Colombia, ese mismo año, el partido Liberal y el partido conservador establecieron un acuerdo que lograría despartidizar el conflicto desatado a partir del asesinato de Jorge Eliecer Gaitán. Pese a que un nuevo conflicto emergió y no ha dado tregua, los dos partidos lograron mantener el control del escenario político, también de manera hegemónica. Los acuerdos políticos, conocidos como el Pacto de Punto Fijo en Venezuela y Frente Nacional en Colombia, hicieron que los dos países recibieran la aprobación de sus élites económicas, así como de los gobiernos de los países poderosos. Pronto fueron reconocidos como ejemplos de estabilidad democrática en un continente plagado de dictaduras y autoritarismos.

No obstante en los años setenta y ochenta, las dos sociedades fueron testigos de fuertes procesos de movilización social popular, que ponían en duda la estabilidad y legitimidad de estas democracias y cuestionaban la exclusión y marginación de amplios sectores sociales ${ }^{1}$. Venezuela experimentó de manera profunda la crisis de sus partidos políticos (AD y COPEl), producto de lo que se ha catalogado como la crisis del modelo rentista-petrolero y de mediación populista, que había garantizado la estabilidad económica y política (Rey, 1991; Salamanca, 1994). Durante los años 80 las tensiones sociales se incrementaron, así como la represión por parte de los actores gubernamentales. En 1988, se produce una masacre en El Amparo, que va a generar el repudio de buena parte de los venezolanos. En 1989, debido a medidas de austeridad decretadas por el Presidente Carlos Andrés Pérez, en su segundo gobierno, los venezolanos se volcaron a las calles y fueron duramente reprimidos por el gobierno. Los hechos generaron la muerte de al menos 400 ciudadanos y un más intenso desprestigio de los partidos políticos y de sus dirigentes (Salamanca, 1999: 239-264; 2003; Puerta, 2006; López M., 1999: 221-238; y 2003: 211-226).

En este contexto, además de las denuncias por la represión de los movimientos sociales, los dirigentes de AD y COPEI serían acusados de corrupción, de haber llevado al país a la debacle económica y de impulsar reformas económicas que empobrecerían aún más a las mayorías (Coronil, 2002). En 1992, dos intentos de golpe de Estado sacuden al país. Carlos Andrés Pérez (1989-1993), afronta la intensificación de la crisis de legitimidad y su gobierno es acusado de apropiación indebida de recursos públicos. La cada vez más importante "política de la calle"

1. Una ampliación sobre la conflictiva relación entre partidos políticos y movimientos sociales en Colombia y Venezuela, puede verse en Blanco (2011: 185-216). 
durante su gobierno (López M., 2003), junto con la pérdida de apoyo de su propio partido (Tanaka, 2008: 107), lo condujo primero a la destitución y luego al autoexilio, acusado de desfalco.

En el caso colombiano, la pérdida de legitimidad de los partidos políticos tradicionales que habían gobernado al país, también de manera hegemónica, pero desde la segunda mitad del siglo XIX, se hace evidente con mayor intensidad a partir de finales de los años 70 y comienzos de los 80. El clientelismo exacerbado (que produjo la autonomización progresiva de las élites regionales), generado por el Frente Nacional (Leal y Dávila, 1990), la intensificación de la violencia política, el narcotráfico, la pobreza, la exclusión y la corrupción generalizada, generaron también movilizaciones sociales que son respondidas con violencia por parte de fuerzas del Estado y actores ilegales, para-estatales (Romero, 2004: 335-376). 1977 puede ser considerado como uno de los años de mayor movilización social en Colombia, pues en septiembre de éste año se desarrolló un paro cívico que ha marcado las conciencias de los luchadores sociales como uno de los más exitosos, pero también como el inicio de una represión estatal y paramilitar intensificada (Múnera, 1998).

En los dos países, entonces, son cada vez más fuertes las tensiones sociales, que los políticos asumen de dos maneras. Mediante la represión y mediante la búsqueda de la relegitimación de las estructuras partidistas. Esta última estrategia se concreta en la aceptación de reformas políticas que amplios sectores de la sociedad civil venían demandando en la búsqueda de ampliar los espacios y canales de participación ciudadana.

En Colombia estas reformas se materializan en al establecimiento de un proceso de descentralización política y administrativa con la elección popular de alcaldes, establecida en 1986 y ejecutada a partir de 1988. En Venezuela, con la creación de la Comisión para la Reforma del Estado (COPRE) a mediados de los años 80, se establece también la descentralización y la elección popular de alcaldes. De este modo, las demandas ciudadanas, que presionaban por una democracia más participativa, posibilitando la entrada de nuevos actores sociales y políticos a las administraciones locales, parecía encontrar respuestas positivas por parte de los gobernantes. No obstante, los partidos políticos profundizan sus crisis y estas reformas van a servir para el surgimiento de nuevos liderazgos con discursos anti-partido y "anti-políticos".

Bajo este marco, el presente documento busca a identificar los elementos que conducen a la crisis y transformación de los sistemas de partidos ${ }^{2}$ de Colombia y Venezuela, históricamente estructuradas políticamente a partir de un modelo bipartidista. Intentamos explicar qué factores

2. Teóricamente, asumimos el concepto de sistema de partido como el sistema de interacciones que es resultado de la competencia entre partidos (Sartori, 1989: 69). En este caso, nos centramos en el papel que han jugado el personalismo, el clientelismo y las reformas institucionales en la supervivencia o transformación del bipartidismo, como sistema de interacción para la sociedad colombiana y venezolana.

ESTRUCTURAS CLIENTELARES Y PARTIDOS POLÍTICOS.

APROXIMACIONES A LA CRISIS Y TRANSFORMACIÓN DE LOS SISTEMAS DE PARTIDOS EN COLOMBIA Y VENEZUELA 
hacen que los partidos políticos pierdan legitimidad y a la postre, como en Venezuela, casi desaparecen del espectro político. Específicamente buscamos explicar por qué, a pesar de que los dos bipartidismos entran en crisis, en Venezuela se produce una fragmentación mayor de los partidos tradicionales, hasta casi desaparecer del espectro político venezolano, mientras que en Colombia, aunque pierden poder, logran mantenerse como fuerzas políticas todavía representativas, al controlar todavía buena parte de los poderes legislativos a nivel nacional y regional y ser muy importantes en las últimas elecciones presidenciales, tanto de Álvaro Uribe Vélez, como de Juan Manuel Santos.

Nuestra hipótesis de trabajo es que el clientelismo y la manera como éste se estructura en cada país, explica el mayor grado de fragmentación de los partidos políticos venezolanos, mientras que, en Colombia, paradójicamente, también el clientelismo sirve de base para una mayor estabilidad del sistema de partidos y específicamente para la sobrevivencia de los dos partidos políticos tradicionales. Asumimos que las estructuras clientelistas venezolanas, fuertemente concentradas, centralizadas y verticales, en las que el líder del partido (que frecuentemente también era o llegaba a ser presidente), resultaron mucho más inestables que las estructuras clientelistas colombianas, muy descentralizadas y desconcentradas.

Para el desarrollo de nuestro objetivo y la argumentación de nuestra hipótesis, partimos de una explicación del clientelismo como concepto político y el modo en que lo entendemos para la interpretación del desarrollo de los bipartidismos de Colombia y Venezuela. En un segundo momento describimos el desarrollo de los bipartidismos de Colombia y Venezuela, mostrando sus elementos comunes y divergentes, particularmente a partir de 1958, momento en el que se constituye el bipartidismo venezolano y el bipartidismo colombiano logra un acuerdo político que pone fin a varios años de violencia, en la que los militantes y simpatizantes de los mismos fueron sus principales víctimas. En la tercera parte, damos cuenta de la manera como estos bipartidismos entran en crisis y de los modos diferenciados mediante los cuales los líderes de los partidos políticos afrontan su pérdida de legitimidad. Finalmente, planteamos cómo estas distintas formas de enfrentar las crisis, conducen a la casi desaparición de los partidos políticos venezolanos y a un repliegue de los partidos colombianos. Todo esto, teniendo como telón de fondo los modos diferentes mediante los cuales operan las estructuras clientelistas.

\section{Clientelismo y sistema político}

El concepto de clientelismo, como categoría de análisis social, surge inicialmente en la antropología y la sociología, aunque luego es retomado por la ciencia política, para comprender las dinámicas de ejercicio del poder, principalmente en sociedades atrasadas (Leal y Dávila, 1990; Corzo, 2006). Desde que comienza a usarse esta categoría, no obstante, no hay acuerdo sobre su significado, sobre las formas de operacionalizarlo para el análisis político (Leal y Dávila, 1990: 37-39), ni sobre el tipo de sociedades en las cuales el mismo podría ser aplicado. Para unos, el 
clientelismo es un fenómeno propio de las sociedades campesinas o atrasadas y es visto como una forma de control social de población subordinada (Powel, 1970: 411-425). Para otros, por el contrario, se trata de formas de intercambio que se dan tanto en sociedades tradicionales como modernas (Corzo, 2006; Leal y Dávila, 1990). De hecho, no hay consenso de cómo juzgar el fenómeno del clientelismo. Para unos, es una forma de manipulación de las relaciones de poder que, por vías ilegítimas (no necesariamente ilegales) destruyen la articulación y funcionamiento de los sistemas políticos y sociales (Sapelli, 1998: 28; citado por Garay, 2008: 32). Para otros, es precisamente lo que sirve de cemento para ciertos sistemas políticos (Leal y Dávila, 1990: 45 y ss.). Incluso se ha afirmado que este puede terminar siendo funcional a la democracia en la medida en que posibilita formas de intercambio válidas entre actores políticos y ciudadanos (Corzo, 2006: 4).

Dentro de este mar de definiciones, seguiremos una estrategia de delimitación del concepto que le apunta a dos razones. En primer lugar, asumiremos el clientelismo como una forma de intercambio de favores políticos (votos) por el acceso a recursos públicos: cargos, proyectos de inversión, contratos, entre otros. Este tipo de intercambio, contrario a las visiones tradicionales, no es del todo asimétrico; es decir, no se da entre agentes políticos todopoderosos que subordinan y manipulan a sectores sociales desprotegidos, sino que los actores sociales subalternos se juegan su propio rol (el de electores), para intercambiar su respaldo con aquel agente político que les ofrezca mayores garantías de contraprestación del servicio recibido. En algunos casos, en este sentido, el clientelismo puede ser considerado una forma de "seguridad social atrasada", o el único medio para algunos sectores sociales de acceder a los recursos del Estado (Camacho, 1998: 51-70). Un elemento más es que el clientelismo no se asume como un intercambio entre personas, sino como un entramado de relaciones de intercambio entre distintos niveles. Diríamos que en primer lugar están los agentes políticos a la cabeza de la transacción, que disponen o pueden llegar a disponer de recursos políticos y económicos público-estatales, a través de elecciones a cargos públicos de distinto nivel; en segundo lugar estarían una serie de intermediarios, que vinculan a los primeros con comunidades regionales y locales, de acuerdo a su posición en la red de influencias. Estos negocian entre sí los respaldos, hacen ofrecimientos a unos y otros, dentro de los partidos o movimientos políticos.

Ahora bien, planteamos que las estructuras clientelares no son iguales en todas las sociedades. En unas, las relaciones clientelares tienden a estar más concentradas que en otras, dependiendo del grado de concentración del poder dentro de la misma estructura del Estado y dentro de las mismas fuerzas políticas. El desarrollo histórico de cada forma depende tanto de estructuras institucionales formales como informales, así como de la capacidad de los actores políticos de romper esta forma de intercambio de bienes públicos por votos, por otras más democráticas; esto es, con menos manipulación de las necesidades y demandas sociales.

En nuestros casos de estudio tenemos a dos sociedades que durante buena parte del siglo XX (a partir de 1958, para el caso venezolano) se caracterizaron por un sistema bipartidista cerrado y 
un fuerte poder del ejecutivo nacional. Dos partidos políticos se convirtieron en los canales de distribución de los recursos públicos y en los vehículos casi exclusivos para el acceso al poder del Estado, en sus distintos niveles. Como complemento de este planteamiento, consideramos que las estructuras clientelares estarían condicionadas por la relación entre economía y política. En el caso de Venezuela, el clientelismo se articula con el rentismo petrolero y la manera en que este se institucionalizó bajo el control casi discrecional del poder Ejecutivo desde la dictadura de Juan Vicente Gómez (Salamanca, 1994: 10-19). En el caso colombiano, por tener una estructura económica más diversificada y una estructura política más descentralizada (no obstante el hecho de que el Estado colombiano sea un Estado unitario y el venezolano uno federal), el clientelismo no logra los niveles de concentración, centralización y verticalidad del caso venezolano.

\section{Desarrollo histórico de los sistemas bipartidistas de Colombia y Venezuela}

Durante el siglo XIX, Colombia y Venezuela viven permanentes estados de inestabilidad, al afrontar varias guerras civiles y frecuentes periodos de dictaduras nacionales o estaduales. En estas, los poderes locales se disputan permanentemente el poder central, sin lograr de manera definitiva su hegemonía nacional (López-Alves, 2003). A partir del siglo XX, las dos sociedades logran constituir regímenes políticos más estables, aunque en el caso de Venezuela las dictaduras fueron una marca central de la primera mitad del siglo XX, hasta 1958. El bipartidismo caracterizó a la sociedad venezolana de la segunda mitad del siglo XX, lo mismo que a la colombiana. Las dos sociedades fueron testigos de acuerdos para el establecimiento de regímenes bipartidistas que buscaban el aseguramiento de la estabilidad del sistema; en Venezuela a este acuerdo se le conoció como el Pacto de Punto Fijo (Molina, 2003a: 490), y en Colombia como Frente Nacional. Las dos sociedades recibieron el apelativo, desde el punto de vista de las élites nacionales, así como internacionales, junto con la sociedad costarricense, de ser las democracias más estables de América Latina (Maingón, 2000). En el caso colombiano, se ha llegado a decir que es la democracia más "antigua y estable" del subcontinente latinoamericano (Blanco, 2008: 51).

\section{a. Clientelismo y partidos políticos en Venezuela}

No obstante, tras estas similitudes y bajo estas calificaciones, se ocultan dinámicas y procesos que diferencian a estas sociedades y que es importante considerar. Esto si queremos comprender por qué los partidos políticos colombianos resultaron mucho más estables y longevos en el siglo XX y lo que va del XXI, mientras que sus homólogos venezolanos han casi desaparecido en el nuevo régimen político de Venezuela.

Así, en primer lugar, es importante tener en cuenta la importancia del caudillismo, como una constante en la historia política de Venezuela (Lynch, 1999, Medina, 2001; Coronil, 2002, 
López, 2006: 65-106). Este tipo de liderazgo logra institucionalizarse en el Estado venezolano gracias dos factores complementarios. De un lado, por los importantes recursos aportados por el petróleo desde comienzos del siglo XX y, de otro lado, debido a la concentración del poder que logran los líderes políticos que llegan a controlar los recursos del Estado, sea por la vía autoritaria o por la vía democrática. Esta concentración del poder y de recursos, es inaugurada por la dictadura de Juan Vicente Gómez (1908-1935); es continuada por la de Marcos Pérez Jiménez (1948-1958), y finalmente heredada, tanto por la democracia de Punto Fijo, como por el nuevo régimen político del chavismo (Molina, 2003b: 169-198).

En segundo lugar, aunque en los dos países terminan por establecerse sistemas bipartidistas fincados en el clientelismo del partido, la forma de ejercicio del poder, de manera tan concentrada en la dirigencia del partido en Venezuela, evoluciona sin embargo hacia una dirigencia históricamente unipersonal (Tanaka, 2008: 89-132), mientras que esta no sería una característica del clientelismo colombiano, en el que el peso de lo regional ha sido muy importante, pese a ser un Estado unitario y Venezuela un Estado Federal. El clientelismo colombiano se constituyó históricamente de una manera mucho más descentralizada y los líderes regionales, particularmente desde el Frente Nacional, han gozado de mucha mayor autonomía que los líderes intermedios de Venezuela.

Ahora bien, contando estas diferencias, en las dos sociedades los partidos políticos se establecieron como los soportes únicos, exclusivos y hasta cierto punto excluyentes de las débiles pero estables democracias. Durante mucho tiempo, cualquier opción por fuera de los mismos fue puesta bajo sospecha, condenada a la marginalidad política u obligando a estas opciones a escoger vías no institucionales y violentas para el acceso al poder, casi desde el mismo momento de constitución de los pactos entre los líderes de los partidos dominantes. En Venezuela, el Partido Comunista Venezolano, así como algunas facciones de Acción Democrática optan por la vía armada, aún después de apoyar y participar de la construcción de la democracia y de apoyar la Constitución de 1961, promovida principalmente por AD y COPEI y la Unión Republicana Democrática, URD (Coronil, 2002). En el caso colombiano, casi desde el mismo momento en que se establece el Frente Nacional surgen las guerrillas históricas y algunos partidos de izquierda fueron perseguidos e incluso eliminados.

En tercer lugar, pese a este elemento, la historia de los dos pactos contiene importantes diferencias. El Pacto de Punto Fijo (PPF), que selló el comienzo de la democracia venezolana, puede ser considerado como un punto de llegada de un proceso que comienza a desarrollarse a finales de la larga dictadura de Juan Vicente Gómez (1908-1935). El fin de éste régimen, que no se produce como resultado de una fuerte movilización social, sino debido a la muerte del dictador por causas naturales, se convierte en el escenario de surgimiento de algunos movimientos sociales y políticos que buscaban la apertura del sistema político, para una creciente clase media excluida del mismo (Herrera, 1999, Salamanca, 2003; Coronil, 2002). El logro del pacto entre las élites que surgen al final del gobierno de Juan Vicente Gómez, no obstante, no se produce 
sin obstáculos, en gran medida debido a las formas clientelares que los partidos políticos heredan del régimen anterior y que usan para intentar concentrar el poder, en el corto periodo que lograron conquistar el poder de Estado, entre 1935 y 1948, particularmente durante el primer gobierno de Acción Democrática (Coronil, 2002). De este modo, antes de lograr acuerdos, los partidos políticos venezolanos tuvieron que minimizar sus aspiraciones, si es que querían alcanzar la estabilidad política.

Cuando finalmente se establece el PPF, este se produce en un contexto de crecientes recursos para el Estado, resultado de la expansión de la explotación petrolera. La amplia disponibilidad de recursos, una vez establecida la democracia electoral, permite el trámite de demandas sociales dentro del marco de la unidad, al menos temporalmente. Venezuela vive una bonanza petrolera, que hace pensar a las élites políticas y económicas, en el definitivo establecimiento de la democracia y en el definitivo control del aparato de Estado por parte de sus burocracias, lideradas por los partidos políticos en el poder.

Para algunos analistas, en este sentido, el Pacto de Punto fijo fue el resultado del aprendizaje de los ciclos anteriores en los que la inestabilidad era la regla. Desde este momento, se le daría prioridad al discurso de la unidad nacional frente a los intereses partidistas, a fin de evitar futuras tensiones o futuros golpes de Estado. Mediante el mismo, se logró la articulación no sólo de las fuerzas políticas partidistas, sino de las organizaciones e instituciones sociales más representativas como la CTV (fundada por un líder de Acción Democrática en 1936); Fedecámaras, fundada en 1944; la iglesia católica y las mismas fuerzas militares. Así, unos partidos con vocación popular y auto-denominados partidos de masas (Herrera, 1999), nacidos dentro de una concepción leninista (Combellas, 2010: 150), logran poner a un lado sus diferencias y estabilizar el sistema político con base en al menos tres factores: a) respeto de las normas constitucionales y resultados electorales, renunciando y oponiéndose a cualquier intento de ruptura ilegal del régimen; b) el principio de la unidad nacional por encima de los intereses partidistas; y c) un programa mínimo común que no podía ser transgredido por ningún partido (López, Gómez y Maingón, 1989: 71, citados por Puerta, 2006: 137-138).

Dentro de este contexto, los recursos del Estado serían el sustento material del PPF y a la postre uno de los factores de su desestabilización. Así, mientras el Estado tuvo abundantes recursos para ser repartidos por las burocracias de los partidos instaladas en el mismo, el sistema se mantuvo estable, pero una vez los recursos escasearon y las demandas continuaron en una curva ascendente, el mismo se desestabilizó (Tanaka, 2008: 89-132). De este modo, la democracia venezolana queda dependiente de los recursos del Estado y de las posibilidades de distribución de sus recursos, constituyendo un sistema que Puerta (2006: 141-142) califica de centralista, presidencialista, populista y estatista. Además de estas características del sistema político que instauran los partidos dominantes, otros autores califican al PPF como militarista, en el sentido en que la militancia del partido impone una disciplina interna rígida, para garantizar el control político de la sociedad y del Estado, así como para restringir el papel de un 
personalismo exacerbado (López, 2006: 65-106). Objetivo este último que no se logra, dado el verticalismo de las estructuras partidistas, como se verá más adelante.

Desde este lugar, se considera que la democracia que se establece en Venezuela a partir del PPF, permite que los partidos políticos extiendan su control hasta copar todo el apartado de Estado; sus poderes, su burocracia y cobertura territorial, así como a los actores de la sociedad civil más representativos, son sometidos al dominio y control de los partido políticos. Lo que se instaura, de este modo, es un corporativismo de Estado en el que los partidos canalizan las demandas de la sociedad, pero únicamente de aquellos sectores articulados bajo su hegemonía. Con este control corporativo del Estado, a la postre los partidos políticos se distancian de los electores que no se someten a las burocracias del partido y esto se va a evidenciar sobre todo a partir de finales de los años 70 y comienzos de los 80.

De esta manera, el sustento popular de estos partidos que se hace presente desde su mismo nacimiento, es sustituido por unas complejas, pero intensamente jerarquizadas redes clientelares, en la que los líderes de los partidos políticos descargan su poder, pese al protagonismo de las masas en sus discursos (Sabino, 1995; Coronil, 2002).

En esta dirección, para algunos autores, la dinámica del auge y caída de los partidos políticos venezolanos, además de depender de los recursos petroleros, se explica también como producto del personalismo y caudillismo propios de la sociedad venezolana, que hicieron inestables las estructuras partidistas y débiles los consensos tanto al interior como al exterior de los mismos, frente a las otras fuerzas políticas (López 2006: 65-106). El surgimiento de nuevas demandas ciudadanas, que cuestionan el clientelismo partidista y la corrupción de los gobiernos, se convierten así en el escenario para el nacimiento de nuevos líderes políticos anti-partidistas, pero muy personalistas (Herrera, 1999) y estos van ganando fuerza, cuando los partidos se burocratizan en extremo, y la corrupción comienza a hacerse visible pero impune (Coronil, 2002); y, finalmente, cuando se permite que nuevos liderazgos de nuevos partidos comiencen a escalar posiciones desde lo local y regional, cuestionando la legitimidad de los partidos políticos hegemónicos ${ }^{3}$.

Desde esta perspectiva se establece que, desde finales de los años 70 y durante la década de los 80, el bipartidismo va perdiendo legitimidad. Las presiones ciudadanas se dirigen cada vez más a la búsqueda de canales no partidistas de trámite de demandas y conflictos. Con los procesos de descentralización política de los años 80, los nuevos liderazgos escalan posiciones; logran insertarse en los gobiernos locales y algunos gobiernos estaduales así como en el parlamento. De

3. No obstante, como se ha hecho mención, el personalismo estaba ya presente en las mismas estructuras partidistas que le daban un gran poder discrecional a los líderes caudillistas de los partidos y hacían difícil el trámite de conflictos internos y una rendición de cuentas horizontal y vertical al interior de los partidos (Tanaka, 2008: 103).

ESTRUCTURAS CLIENTELARES Y PARTIDOS POLÍTICOS.

APROXIMACIONES A LA CRISIS Y TRANSFORMACIÓN DE LOS SISTEMAS DE PARTIDOS EN COLOMBIA Y VENEZUELA 
esta manera se logra establecer una relativa independencia de los poderes, aunque también una mayor inestabilidad en los sistemas político y de partidos (Muñoz y Pineda, 2003: 45-74).

Las protestas sociales y el discurso anti-partido y anti-político de varios sectores sociales encuentran eco en los medios de comunicación y al final en los mismos líderes de los partidos tradicionales, restándole legitimidad a las estructuras partidistas (Antillano, 2005: 205-218; Ellner, 2003: 157-178; García-Guadilla, 1997: 9-23; 2001: 113-132; 2003: 31-62; 2005; Grohmann, 1996; Lander, 1994; López M., 1999: 221-238; López M., y Lander, 2006: 11-30; López S. y Hernández, 2001: 661-666). Así, los conflictos sociales que los gobiernos del Pacto de Punto Fijo no pueden tramitar en un contexto de recursos limitado (y a los cuales responden con represión), junto con los procesos de descentralización y la posibilidad de elegir directamente a alcaldes y gobernadores a finales de los años 80, debilita la imagen de los partidos y, a la postre, la estabilidad de la democracia de Punto Fijo. Podría decirse que este proceso culmina con el triunfo electoral en 1993, del otrora jefe casi absoluto de COPEI, pero disidente del mismo (Rafael Caldera), quien se presenta a las elecciones a nombre de un movimiento político fundado para la ocasión, por él mismo (Álvarez, 2003: 75-93; Tanaka, 2008: 89-132).

Para sintetizar un poco, podríamos decir que, en términos históricos, la vida del PPF, aunque se extiende de 1958 a 1993, tiene su auge a mediados de los 70, con el primer Gobierno de Carlos Andrés Pérez, pero por la corrupción, clientelismo y las protestas sociales en aumento, pierde legitimidad. A partir de los años 70, las protestas sociales se orientan hacia la búsqueda de mayor participación ciudadana, a la profundización de la descentralización y la elección popular de alcaldes y gobernadores estaduales con el fin de frenar el control clientelar del bipartidismo, lo que logran, finalmente, de manera parcial, a mediados de los 80, momento en el cual se impulsan una serie de reformas políticas y administrativas (Antillano, 2005: 205-218; Ellner, 2003: 157-178; García-Guadilla, 1997: 9-23, 2001: 113-132, 2003: 31-62, 2005; Grohmann, 1996; Lander, 1994; López M., 1999: 221-238; López M. y Lander, 2006: 11-30; López S. y Hernández, 2001: 661-666). Este periodo de reformas se extiende desde el gobierno de Lusinchi (1983-1988), hasta el segundo gobierno de Caldera (1993-1998), momento en el cual se le da sello de defunción al bipartidismo puntofijista y se abren los espacios para la constitución de un nuevo régimen político, que se consolidará con la hegemonía del chavismo (López M. y Lander, 2000: 9-17; López, 2006: 65-106; Maingon, et al, 2000: 91-124; López M., y Lander, 1999 : 4-19; Combellas, 2010: 149-174; Gómez C. et, al, 2010: 33-100).

Otro factor que hay que mencionar como característica del sistema político venezolano y que le da una particularidad a la forma en que se estructuró su bipartidismo, es el poder que el Ejecutivo ha tenido históricamente, debido tanto a los recursos que ha manejado desde el boom petrolero, como a la concentración del poder, dentro del PPF. Una concentración que se reproducía desde los secretarios y presidentes de los partidos políticos. Esto, institucionalmente y a pesar de ser Venezuela un Estado Federal (Hernández, 2005: 95-116), trajo como consecuencia un fuerte centralismo que puso a disposición del ejecutivo y sus ministros, una gran cantidad de 
recursos que se repartían de manera clientelar, corrupta y vertical dentro de la militancia del partido (Coronil, 2002). Viviendas para sectores populares, de clase media y media alta urbana, legalización de barrios, así como distribución de cargos burocráticos y contratos, eran tramitados y repartidos siguiendo una estricta línea de mando. Para el acceso a estos recursos, incluso los militantes de los partidos debían probar su pertenencia a los mismos a través de diplomas o actas de vinculación (Aragort, 2004: 553-560; Ellner, 2003: 157-178). Esta institucionalización del clientelismo vertical, concentrado y centralizado se hizo posible desde la misma constitución de 1961, que dio al ejecutivo un poder superior a legislativo. La misma estructura partidista hacía que las listas para el Senado (cerradas y bloqueadas) las hiciera la dirigencia del partido, con base en una lealtad probada de los aspirantes al Congreso, o aspirantes a la reelección (Sabino, 1995; Lucena, 2003: 245-265; Aragort, 2004: 553-560). Para tal fin, los líderes políticos de segundo orden debían probar su capacidad de mover electores tanto en el plano nacional como regional. Esta articulación entre el sistema político y el sistema de partidos contribuyó, hasta los años 90, a un predominio de la dirigencia de los partidos que se materializaba en el ejecutivo, sobre otras fuerzas sociales.

Como se enunció antes, los años 70 y 80 fueron para Venezuela un periodo de intensas movilizaciones sociales, muchas de las cuales se orientaban a la construcción de una nueva estructura política de participación (anti-partidista) y una nueva estructura estatal. En 1984, se creó la Comisión Para la Reforma del Estado, COPRE, con el fin de adelantar discusiones y elaborar propuestas para fortalecer la descentralización y la participación ciudadana. Esto condujo a la elección popular de alcaldes en 1988 y de gobernadores a partir 1992, todo en medio del impulso de políticas neoliberales que no redujeron las protestas sociales, sino que las hicieron más intensas.

Pese a los efectos posteriores, el objetivo buscado por los líderes de los partidos políticos, mediante las reformas de finales de los años 80 , era relegitimar al bipartidismo y combatir el clientelismo centralizado que lo caracterizaba, por la vía de una mayor participación ciudadana en temas de nivel local y territorial (Brewer-Carías, 2005: 73-96). No obstante, como bien señala Hernández (2005: 95-116), las reformas ataron la toma de decisiones de carácter económico al ejecutivo nacional, con lo que la descentralización sufrió un duro revés. Durante los años 90, se siguió pugnando por una reforma del régimen político, una mayor participación ciudadana y el abandono del puntofijismo, lo que no se lograba todavía totalmente, pero que a la postre sirvió de base para el protagonismo político de Hugo Chávez, quien lideró un intento de golpe de Estado el 4 de febrero de 1992 y quien con el tiempo se convertiría en el sepulturero del régimen anterior (Gómez C., et al, 2010: 33-100; Combellas, 2010: 149-174).

Durante el gobierno de Hugo Chávez y ahora de su heredero Nicolás Maduro, algunos consideran que se ha reconcentrado el poder; que se han roto los sistemas de balance y contrapesos entre los poderes del Estado con una constitución que favorece al ejecutivo y un sistema 
político que ha debilitado las estructuras partidistas y el control político tanto horizontal como verticalmente (Brewer-Carías, 2005: 73-96; López, 2006: 65-106; Maingon, 2000: 91-124; Canache, 2002: 69-90; Hellinger, 2005: 8-32; Mascareño, 2007: 11-22; Tanaka, 2008: 89-132; Calcaño, 2010, Combellas, 2010: 149-1744).

Aunque no hay acuerdo sobre los calificativos ni sobre las bases del nuevo sistema y hay opiniones que defienden el carácter democrático electoral del nuevo gobierno (Murillo, Oliveros y Vaishnav, 2010: 87-114), o presentan el sustento social del Chavismo, incluso desde antes de 1992 (Valencia, 2005: 79-97), el hecho es que se ha configurado un régimen en el que buena parte de los recursos y las decisiones políticas, jurídicas y económicas pasan por las manos del ejecutivo nacional; esto a su vez le ha dado un peso mayor al régimen del que ya tenía dentro del puntofijismo y dentro de las reformas de los años 80 (Hernández, 2005: 95-116, BrewerCarías, 2005), lo que favorece el clientelismo centralizado y concentrado, así como la inestabilidad del gobierno, el cual, nuevamente, queda a merced de la disponibilidad de recursos petroleros para satisfacer las demandas sociales.

\section{b. Clientelismo y partidos políticos en Colombia.}

Como en el caso venezolano, el bipartidismo colombiano, desde 1958, se estableció como el canal exclusivo para el trámite de intereses y demandas sociales, políticas y económicas a través de un pacto similar, pero mucho más excluyente al PPF: El Frente Nacional (FN). Para nuestros propósitos, la historia del bipartidismo colombiano puede dividirse en tres momentos. Un periodo de formación conflictiva, que va desde mediados (incluso comienzos) del siglo XIX hasta comienzos del siglo XX (López-Alves, 2003); un periodo de relaciones pacíficas, hasta los años 30 del siglo XX y uno de violencia extrema, entre los años 40 y 50 del mismo siglo, hasta la dictadura de Rojas Pinilla y el establecimiento del FN, como mecanismo para "despartidizar" la violencia.

Para el tema que nos interesa en este trabajo, el periodo que comienza con el Frente Nacional, es para algunos el momento en el cual las identidades partidistas comienzan a resquebrajarse, sin que los partidos políticos pierdan su poder (Leal, 1989: 21-62; González, 1993; Gilhoes, 1993: 69-114; Gutiérrez, 2002: 25-78, 2007). Este es un periodo en el que además se establece el clientelismo, como característica principal del sistema político colombiano (como sostienen Leal y Dávila, 1990).

Ahora bien, la característica principal de este clientelismo es su carácter regional y la relativa autonomía de los "patrones" regionales y locales frente a las propias estructuras partidistas y específicamente frente a sus líderes nacionales (González, 1980; Leal y Dávila, 1990; Gutiérrez,

4. Buena parte de estos autores se refieren al régimen chavista como autoritarismo competitivo. 
2002: 25-78, 2007). De este modo, la relativa disciplina de partido ganada en los periodos anteriores se pierde a partir del Frente Nacional y son cada vez más las manifestaciones de insubordinación de los otrora considerados "políticos profanos"; es decir, de aquellos encargados de movilizar en los departamentos, ciudades, pueblos y zonas rurales a los electores cada vez que era necesario (Wills, 2002). De este manera, contrario al clientelismo venezolano, lo que sucede a partir del $\mathrm{FN}$, es una creciente autonomía regional en términos político-electorales debido a que, de hecho, desde las élites se establece un régimen en el que pierden importancia las identidades partidistas a la hora de las elecciones, por el sistema de rotación en el poder y de repartición simétrica de la estructura burocrática del estado (Gutiérrez, 2007).

Esto, no obstante, no hace que los partidos políticos tradicionales pierdan el poder y la capacidad de movilizar electores, dentro de los márgenes históricos de abstención que han sido mucho mayores en el caso venezolano (hasta finales de los años 80) y que habían rondado siempre el $50 \%$ de participación electoral.

Las características de éste sistema político, basado en el clientelismo, son: la movilización electoral local, articulada a los niveles regionales y nacionales. Hasta 1988 los alcaldes son designados por los gobernadores y estos a su turno por el presidente de la república. Desde 1992 los gobernadores son elegidos popularmente.

Un elemento que además favorecía el trámite clientelar, descentralizado y desconcentrado de recursos, proyectos, presupuesto y cargos públicos, fue la reforma política impulsada por el gobierno de Alberto Lleras Camargo, que le otorgaba partidas presupuestales a los congresistas para impulsar proyectos de inversión en sus departamentos. Esta reforma apuntaló los capitales políticos de los gamonales regionales históricos, pero también incrementó la conflictividad al interior de los partidos por el acceso a cargos de elección popular, particularmente los legislativos nacionales, departamentales y locales (Leal, 1989; Leal y Dávila, 1990; Pizarro, 2002; Pachón, 2002: 78-131; Rodríguez-Raga, 2002: 221-260).

De este modo, entre 1968 y 1988, con la posibilidad de controlar un amplio margen de cargos públicos, de contar con recursos públicos como si fueran propios, para mantener a las redes clientelares, en un Estado y una sociedad en proceso de modernización y con crecientes recursos, el Congreso y los legislativos regionales se convirtieron en los escenarios institucionales que establecieron al clientelismo desconcentrado y descentralizado, como característica fundamental del sistema político colombiano. A la postre, esto también sirvió de base para que el sistema de partidos lograra la estabilidad suficiente para enfrentar un conflicto armado interno violento y duradero, crecientes protestas sociales y el surgimiento de movimientos disidentes como la Alianza Nacional Popular, del exdictador Gustavo Rojas Pinilla o el Movimiento Revolucionario Liberal, liderado por Alfonso López Michelsen, así como, más adelante, a movimientos alternativos de izquierda, como la Unión Patriótica o el M-19 (Leal, 1989). 
En términos analíticos, el clientelismo que se instaura es uno en el que una amplia red de "patrones" que van de lo local a lo nacional, trabajan para el mejor postor, muchas veces perteneciente a facciones distintas al interior de un mismo partido o incluso para líderes de partidos distintos. Estas amplias redes tienen vínculos que aunque se mantienen a lo largo del tiempo, son cada vez más vulnerables a las divisiones internas tanto del Partido Liberal, como del Partido Conservador. Se habla, en esta dirección, de casas o familias que gobiernan la política regional y local; que cambian de facción (se agrupan con familias más poderosas a nivel local y regional, para al finalizar, aliarse con los líderes nacionales de cada partido (Gutiérrez, 2002: 25-78, 2007; Leal y Dávila, 1990; Leal, 1989, Hylton, 2010).

En este contexto, aunque el poder presidencial es considerable, siempre tiene que negociar con los caciques regionales que controlan el Congreso y a su vez controlan las redes clientelares de nivel regional y local (González, 1980, 1993: 15-68; Leal y Dávila, 1990; Pachón, 2010 : 47-78).

Así como en Venezuela, durante los años 70 y 80, son crecientes las movilizaciones que buscan abrir el sistema político, luchan contra el clientelismo y por hacer del país una democracia participativa y descentralizada. No obstante, a diferencia de Venezuela, el conflicto interno marca el desarrollo de las luchas civiles y de hecho se convierte en excusa para las élites políticas, para frenar cualquier intento de democratización no controlada por las mismas (Pizarro, 1990: 411-443). Pese a esto, el sistema se abre hacia una descentralización administrativa que, aunque moderada, es mucho mayor que la que se dio en Venezuela, particularmente en el nivel local y regional, desde finales de los años 80 y principios de los 90 (Hernández, 2005: 95-116). Con esto no se elimina el clientelismo, sino que se multiplica aún más, en la medida en que las clientelas creadas durante el Frente Nacional adquieren mayor independencia, pues ya no necesitan el aval de un "patrón" superior, para acceder al poder institucional local y a sus recursos.

Se multiplican así, desde los finales de los 80, las redes clientelares con mayores autonomías. El sistema político se fragmenta aún más con la constitución de 1991, que profundizó la descentralización administrativa y posibilitó la creación de cientos de movimientos políticos de alcance municipal, aunque también muchos de alcance regional y nacional. La década de los 90 es, en esta dirección, un periodo en el que el faccionalismo se hace extremo (Molina, 2004). Se posibilita el surgimiento de líderes carismáticos a nivel regional y de grandes ciudades por fuera del control de los partidos políticos y estos adquieren luego protagonismo nacional, constituyendo lo que Pizarro (2010) denomina como "microempresas electorales".

Es tan fuerte este sistema, que ni siquiera las más duras crisis económicas (claro, no comparables con las de otros países de América Latina), el duradero conflicto armado interno, las protestas sociales, ni el surgimiento de fuerzas políticas alternativas al bipartidismo, logran disputar el control del electorado, ni las dinámicas de acceso al poder en el ámbito nacional. Ahora bien, aunque el bipartidismo como tal pierde cada vez más protagonismo y legitimidad, no así sus 
líderes regionales históricos. La década de los 90 y lo que va del nuevo siglo, es el escenario para el surgimiento de facciones que se autoproclaman partidos independientes, tanto para cargos ejecutivos locales, regionales y nacionales, como para las elecciones al congreso y la presidencia. Esto ha hecho que los dos bloques de poder que eran el Partido Liberal y el Partido Conservador, pierdan presencia al interior del Congreso (Senado y Cámara), en términos relativos, aunque en términos absolutos, cambian las etiquetas, pero no los protagonistas (Pizarro, 2002; Molina, 2004; 2010).

De este modo, a diferencia del caso venezolano, el clientelismo colombiano, por estar desconcentrado y descentralizado, tiene formas de articulación, diríamos más horizontales, lo que hace que si un líder local, regional o nacional pierde vigencia, popularidad, o control de la red de poder, sea fácilmente remplazado por otro, sin que se causen mayores traumas en el sistema en su conjunto.

Así, pese a las transformaciones de forma, la particular estructura colombiana de clientelismo sigue teniendo vigencia y sirve de soporte para la estabilidad del sistema político colombiano, ahora dentro de un multipardisimo moderado (Tanaka, 2008: 93; Pachón, 2010: 47-78). A diferencia del caso venezolano, en Colombia el poder del Ejecutivo no ha podido convertirse en un poder de las dimensiones del poder del ejecutivo venezolano, debido a que las estructuras políticas e institucionales que lo soportan (entre ellas las redes clientelares), no se han concentrado tanto como en Venezuela, tanto antes de Chávez, como con Chávez en el poder y ahora con su sucesor, Nicolás Maduro. En esta dirección, podríamos plantear que ni siquiera el gobierno de Álvaro Uribe Vélez (2002-2010), quien siendo de origen liberal samperista (de las filas del expresidente Ernesto Samper, 1994-1998) y haber llegado al poder por un movimiento político creado por él mismo (Primero Colombia), logró permanecer en el poder por más de dos periodos consecutivos, debido a que ponía en peligro el "equilibrio" de poderes de las redes clientelares regionales y locales, así como de las oligarquías tradicionales de los partidos, particularmente del partido liberal, y amenazaba con concentrar el poder de las mismas en sus propias manos.

Lo anterior podría argumentarse teniendo en cuenta que el referendo que impulsaba su segunda reelección se cae por "vicios de trámite" a pesar de ser agenciado por expertos juristas y tener un respaldo popular sin precedentes en la historia política de Colombia al finalizar el periodo presidencial.

De este modo, se pone en evidencia la gran capacidad de adaptación que tiene este clientelismo descentralizado y desconcentrado, primero dentro de la estructura del bipartidismo (González, 1993: 15-68; Gutiérrez, 2002: 25-78) y luego dentro del multipartidismo que se configura en lo que va del siglo XXI (Gutiérrez, 2007; Molina, 2010).

El personalismo ha sido muy importante en el desarrollo de la política colombiana contemporánea pero, al no contar con las estructuras institucionales de soporte suficientes para 
consolidarse, no logra romper con las estructuras partidistas tanto tradicionales como nuevas, sean estas alternativas o disidentes a/del bipartidismo tradicional. En buena media este relativo poder de los liderazgos personales obedece a factores institucionales. En el caso venezolano, desde antes de la llegada de Hugo Chávez, el poder del Ejecutivo Nacional, tanto en términos de autonomía presupuestal como debido a su poder legislativo, ha sido considerablemente mayor que en el caso colombiano (Hernández, 2005: 95-116). Si bien desde antes de la constitución de 1991 había cierta discrecionalidad legislativa del presidente en Colombia, a través de la posibilidad de declarar Estados de Excepción y legislar "por decreto" (Pachón, 2010: 4778), el presidente no podía hacerlo de manera indeterminada en el tiempo. Este poder se va a limitar mucho más a partir de la constitución de 1991 y ni siquiera la gran popularidad de Uribe, después del 2002, lograron romper la relativa autonomía del Legislativo y la particular "independencia de poderes" que caracteriza al sistema político colombiano. Esto se puede confirmar a través de las dificultades que el Ex presidente Uribe, hoy convertido en "líder de la oposición" (Semana, 2012), tiene para articular a sus huestes y negar o frenar las iniciativas del gobierno de Juan Manuel Santos.

En el caso colombiano, además de lo anterior, las reformas jurídicas no han tendido, como en el caso venezolano, a desestructurar los partidos políticos o a eliminarlos, sino que le han apuntado, con relativo éxito, a fortalecerlos. Esto ha sucedido particularmente con la reforma de 2003 y con la posterior ley de bancadas que busca fortalecer la disciplina de los partidos (Pachón, 2010: 47-78) y evitar lo que se ha conocido como travestismo político. Así, aunque efectivamente buena parte de los partidos, incluidos las "tercerías", se comportan desde los noventa, sobre todo, como "microempresas electorales" (Pizarro, 2008: 133-162), una tradición clientelista, unas estructuras de relaciones políticas que articulan lo local, lo regional y lo nacional, dificultan un mayor peso del personalismo, aunque también el fortalecimiento de fuerzas contrahegemónicas al bipartidismo y sus disidencias.

En el caso venezolano, como muestran varios autores, las reformas del régimen chavista han fortalecido su propia hegemonía y debilitado las estructuras organizativas autónomas, incluido su propio partido (Combellas, 2010: 149-174; Gómez C. et al, 2010: 33-100). En Colombia, si bien han surgido líderes personalistas que amenazan a los partidos políticos, las estructuras de los mismos no han permitido su desaparición como estructuras organizativas, medianamente estables, aunque no hayan identidades partidistas y vínculos con la sociedad tan estables, como se esperaría o desearía (Mainwaring, 2002: 11-22).

\section{CONCLUSIONES}

Por lo planteado en este documento, las estructuras de las dos formas de bipartidismo, debido al papel del personalismo, el clientelismo (en sus formas diferenciadas) y por las reformas institucionales implementadas, han tenido desenlaces diferentes en cada sociedad. El peso del 
personalismo, como se expuso, se ha incrustado de manera mucho más profunda en la sociedad venezolana, tanto desde el punto de vista cultural e histórico, así como institucional (Lynch, 1991; Medina, 2001; López M. y Lander, 2006: 11-30). Este personalismo sirvió de base incluso para que, por ejemplo, desde el mismo gobierno (segundo gobierno) de Carlos Andrés Pérez, se actuara por fuera del partido que lo llevó dos veces al poder: Acción Democrática. El mismo personalismo es el que hace que Rafael Caldera llegue, también a su segundo gobierno, por fuera del partido que él mismo ayudó a fundar: COPEl. Esto llevó, en el caso venezolano, a que los gobiernos gobernaran sin sus partidos. El segundo gobierno de Carlos Andrés Pérez desplazó a los líderes de los partidos y se apoyó en técnicos en planificación para llevar a cabo sus reformas de ajuste estructural (Tanaka, 2008: 89-132).

Ahora bien, este elemento no puede considerarse como movilizador exclusivo de la debacle del bipartidismo venezolano. Un clientelismo concentrado y centralizado, que se instaura históricamente en Venezuela con el establecimiento de la democracia electoral bipartidista en 1958, sobrevive a la crisis del bipartidismo puntofijista, y adquiere mayor profundidad en el gobierno de Hugo Chávez. De alguna manera, las dinámicas del conflicto por el poder en Venezuela hacen que la única forma de resistir sea concentrando cada vez más el poder, para aumentar la capacidad de maniobra del ejecutivo nacional, y con esto, concentrando aún más la toma de decisiones y los mecanismos de trámite de demandas e intereses sociales. Los bloqueos, paros, protestas y manifestaciones sociales de la oposición en Venezuela, han hecho que el Gobierno de Hugo Chávez y ahora de su sucesor, con el respaldo de sus aliados, concentre cada vez más el poder y se radicalicen las posiciones. Con esto, el chavismo se hace más fuerte, pero a la vez más débil, en tanto, las demandas sociales y los conflictos que se generan cada vez desbordan más su capacidad de trámite clientelista.

De este modo, lo que le pasó a los partidos del puntofijismo puede, eventualmente, sucederle al chavismo, con el agravante de que la oposición, en aquellos lugares donde ha mantenido el poder institucional, ha reproducido las prácticas excluyentes, clientelistas y personalistas. Esto mismo, paradójicamente, hace que la oposición impulse un liderazgo caudillista, para enfrentar al caudillismo y personalismo chavista ${ }^{5}$ (Gómez C. et al, 2010: 46), lo que le ha permitido en el actual proceso electoral, por primera vez, presentarse a las últimas contiendas electorales para presidencia de manera unificada.

En el caso colombiano el proceso de autonomización de las "camarillas" clientelistas locales y regionales, "al son" de los calendarios electorales, ha hecho del sistema político un sistema fundamentalmente clientelar. Este clientelismo, dadas sus particularidades, ha resistido los embates

5. Algunos autores, no obstante, consideran que la actual "unidad" de la oposición venezolana es el resultado de la reducción del personalismo (Gómez-Calcaño, 2010). Por nuestra parte, consideramos que es todo lo contrario. Se logra la unidad, pero se fortalece sólo un liderazgo, que se asume como el único capaz de disputar el poder del personalismo chavista.

ESTRUCTURAS CLIENTELARES Y PARTIDOS POLÍTICOS.

APROXIMACIONES A LA CRISIS Y TRANSFORMACIÓN DE LOS SISTEMAS DE PARTIDOS EN COLOMBIA Y VENEZUELA 
de las crisis económicas, movimientos sociales, un conflicto armado que dura ya más de 50 años y el surgimiento de líderes políticos que, gracias a las fortalezas del sistema, no logran desestabilizarlo y que, por el contrario, pareciera que lo vigoriza. Esto en la medida en que, para acceder o conservar el poder, por parte de las nuevas fuerzas, al menos desde finales de los 80 hasta la actualidad, han tenido que incorporar prácticas clientelistas, que terminan por debilitar sus posibilidades de ampliar sus bases electorales.

En términos más precisos, para ganar elecciones en Colombia, se necesita unas bases electorales lo suficientemente amplias, como para disputar el poder a aquellos que controlan o pueden controlar las redes clientelares regionales y locales. Para esto, o se incorporan prácticas clientelares (poniendo en riesgo el voto de opinión de las clases medias y medias-altas urbanas y rurales), o se apela a un voto de opinión restringido, que no alcanza para disputar el poder nacional y, por tanto, las nuevas fuerzas políticas sólo pueden acceder al poder local o regional, como ha sido el caso de Bogotá y algunas ciudades importantes, así como de algunos departamentos.

De este modo, se asegura la reproducción de las formas de hacer política, tanto en un país como en otro y, en los dos casos, el clientelismo contribuye a la vez a la inestabilidad (en Venezuela) como a la estabilidad de los sistemas políticos, debido a las formas en que este fenómeno se manifiesta.

Finalmente, tenemos el elemento institucional formal, esto es, la manera como se han desarroIlado reformas a los sistemas de partidos, o reformas políticas que han permitido la subsistencia de los partidos políticos tradicionales en Colombia, aunque compartiendo el escenario con fuerzas disidentes que tienden a consolidarse, así como con movimientos alternativos. Todavía subsiste el fantasma del "transfuguismo político" y la lucha de las élites regionales por autonomizar su poder frente a las estructuras partidistas, pero no han logrado que sus iniciativas se materialicen en reformas políticas. Por el contrario, las últimas reformas políticas en Colombia han tendido a fortalecer a los partidos y la disciplina interna, llevando al tránsito de un bipartidismo a un multipartidismo moderado (Tanaka, 2008: 89-132; Pachón, 2010: 47-78). Lo opuesto ha sucedido en Venezuela, aunque, por las dinámicas del conflicto, es también posible que se reconfigure el sistema político, ya sea hacia un nuevo bipartidismo (chavistas vs. oposición), o ya sea hacia un sistema de partido hegemónico.

Para concluir, es importante plantear que, para comprender los procesos de transformación de los sistemas de partidos, es necesario atender a la complejidad de los mismos, no fijándose exclusivamente en factores estructurales, como hacen algunos autores, pero tampoco en los factores tan coyunturales y personales, como lo hacen otros. Es necesario atender a la complejidad de los sistemas, teniendo en cuenta incluso las dinámicas y prácticas consuetudinarias, como el clientelismo. Personalismo, clientelismo y reformas, son dimensiones que juegan un papel importante en los procesos de transformación de los sistemas políticos de Colombia y Venezuela, aunque de manera diferenciada, debido a las formas particulares de relaciones entre las mismas. 


\section{REFERENCIAS}

- Álvarez, Á. E. (2003), De la Hegemonía partidista a la democracia sin partidos. Politeia, 30 (30), 75-93, ene. Recuperado en bril de 2012 de la Edición digital: http://www2.bvs.org.ve/ scielo.php?script=sci_arttext\&pid=S0303-97572003000100006\&lng=es\&nrm=iso.

- Antillano, A. (2005). La lucha por el reconocimiento y la inclusión en los barrios populares: Las experiencias de los Comités de Tierras Urbanas. Revista Venezolana de Economía y Ciencias Sociales, 11 (3), 205-218.

- $\quad$ Aragort, S. Y. (2004). La democratización en los espacios de poder local y el clientelismo político. Parroquia Osuna Rodríguez (Municipio Libertador del Estado de Mérida). Fermentum. Revista Venezolana de Antropología y Sociología, 14 (41), 533-560.

- Blanco S. (2008). La democracia colombiana en el discurso de la Prensa: El Tiempo, 19902004. La democracia amenazada. Administración \& desarrollo, 45, 47-81.

- Blanco S. (2011), Partidos políticos y Sociedad Civil en Colombia y Venezuela. Verva luris, 1 (25), 185-216.

- $\quad$ Brewer-Carías, A. (2005). Los problemas de la gobernabilidad democrática en Venezuela: El autoritarismo constitucional y la concentración y centralización del poder. En: D. Valdás (ed.), Gobernabilidad y constitucionalismo en América Latina (pp. 73-96) México: Universidad Nacional Autónoma de México - Instituto de Investigaciones Jurídicas.

- Camacho, G. (1998). Democracia, exclusión y construcción de lo público en Colombia. En: A. Valencia (ed), Exclusión social y construcción de lo público en Colombia (pp. 51-70). Bogotá: CIDSE-CEREC.

- $\quad$ Canache, D. (2002). From Bullets to Ballots. The emergence of popular support for Hugo Chavez. Latin American Politics and Society, 44 (1), 69-90.

- Combellas, R. (2010). La Venezuela de la V República: La reforma política y sus implicaciones institucionales. En M. Tanaka, F. Jácome (eds.), Desafíos de la gobernabilidad democrática. Reformas político-institucionales y movimientos sociales en la región andina (pp. 149-174). Lima: Instituto de Estudios Peruanos.

- Coronil, F. (2002). El Estado mágico. Naturaleza, dinero y modernidad en Venezuela. Caracas: Consejo de desarrollo científico y humanístico de la Universidad Central de Venezuela.

- $\quad$ Corzo, F. (2006). El clientelismo político como intercambio. Barcelona: Institut de ciéncies politiques i socials, Work Paper, 206. 
- $\quad$ Ellner, S. (2003). Tendencias recientes en el movimiento laboral venezolano: Autonomía vs control político. Revista Venezolana de Economía y Ciencias sociales, 9 (3), 157-178.

- Garay, S. (2008). La captura y reconfiguración cooptada del Estado en Colombia, Método. Bogotá: AVINA y Corporación Transparencia por Colombia.

- García-Guadilla, M. (2001). El movimiento ambientalista y la constitucionalización de nuevas racionalidades: dilemas y desafíos. Revista Venezolana de Economía y Ciencias Sociales, 7 (1), 113-132.

- $\quad$ García-Guadilla, M. (1997). Sociedad civil, democracia liberal y economía de mercado. Las organizaciones sociales liberales en Venezuela. Encuentro de la Asociación de estudios Latinoamericanos en México, 9-23.

- García-Guadilla, M. (s. f). La sociedad civil venezolana (1961 - 2004). Institucionalización de nuevas ciudadanías y luchas por la democracia. Recuperado en marzo de 2012 de: www.gumilla.org.ve/.../LA\%20SOCIEDAD\%20CIVIL\%20VENEZOLANA.doc?PHPSESSID $=023310 \mathrm{c} 672 \mathrm{fcb} 614 \mathrm{~d} 75 \mathrm{f} 2 \mathrm{e} 1 \mathrm{~d} 262 \mathrm{~d} 3353$ (Borrador).

- $\quad$ García-Guadilla, M. (2003). Politización y polarización de la sociedad civil venezolana: las dos caras frente a la democracia. Espacio Abierto, 12 (1), 31-62.

- $\quad$ Gilhoes, P. (1993). Sistema de partidos y Partidos políticos en Colombia. En: O. Delgado, F. Gonzáles y otros. Modernidad, Democracia y Partidos Políticos (pp. 69-114). Bogotá: FIDEC-FESCOL.

- Gómez C., et al (2010). Venezuela: Democracia en Crisis. En: M. Cameron y J. Luna, Democracia en la región andina (pp. 33-100). Lima: Instituto de Estudios Peruano.

- González, F. (1980). Clientelismo y administración pública. Enfoques Colombianos, 14 (pp. 67-106). Bogotá: Fundación Friederich Nauman,

- $\quad$ González, F. (1993), Tradición y modernidad en la política colombiana. En: O. Delgado, et al., Modernidad, democracia y partidos políticos (pp. 15-68). Bogotá: FIDEC-FESCOL.

- $\quad$ Grohmann, M. (1996). Macarao y su gente. Movimiento popular y autogestión en los barrios de caracas. Caracas: Instituto Latinoamericano de Investigaciones Sociales -ILDIS Nueva Sociedad.

- $\quad$ Gutiérrez, S. (2007). ¿Lo que el Viento se Llevó? Los partidos políticos y la democracia en Colombia, 1958-2002. Bogotá: Editorial Norma. 
- Gutiérrez, S. (2002). Historias de democratización anómala. El Partido Liberal en el Sistema Político Colombiano desde el Frente Nacional hasta hoy. En: S. Gutiérrez (Comp.), Degradación o cambio. Evolución del sistema político colombiano (pp. 25-78) Bogotá: Editorial Norma.

- Hellinger, D. (2005). When "No" Means "yes" to Revolution: Electoral politics in Bolivarian Venezuela. Latin Américan Perspectives, 32 (3), Venezuelan Exceptionalim Revisited: New perspectives on politics an Society, 8-32.

- Hernández, B. (2005). Nivel territorial intermedio en Colombia y Venezuela. Provincia, 15, 95-116.

- Lander, E. (1994). Neoliberalismo, sociedad civil y democracia: ensayos sobre Venezuela y América Latina. Caracas: FACES-Universidad Central de Venezuela.

- Leal, B. y Dávila, A. (1990). Clientelismo: El sistema Político y su expresión regional. Bogotá: IEPRI-UNAL, Tercer Mundo Editores.

- Leal, B. (1989). Estabilidad macroeconómica e institucional y violencia crónica. En: B Leal (Comp.). En busca de la estabilidad perdida. Actores políticos y sociales en los noventa (pp.21-62). Bogotá: TM Editores, IEPRI-UN, Colciencias.

- López, M. (2003). Movilización, institucionalidad y legitimidad en Venezuela. Revista Venezolana de Economía y Ciencias Sociales, 19 (1) 211-226.

- López, M. y Lánder, E. (2000). Elecciones de 2000 en Venezuela. Implantación de una nueva hegemonía. En Anuario social y Político de América Latina y el Caribe, 4, 9-17.

- $\quad$ López, M. y Lánder, L. (1999). Venezuela: La victoria de Chávez. El Polo Patriótico en las elecciones de 1998. Revista Nueva Sociedad, (160) 4-19

- $\quad$ López, M. y Lánder, L. (2006). Novedades y continuidades de la protesta popular en Venezuela. Revista Venezolana de Economía y Ciencias Sociales (12) 11-30.

- López, M. (1999). La protesta popular venezolana entre 1989 y 1993 (en el umbral del neoliberalismo). En: M. López (ed.), Lucha popular, democracia, neoliberalismo: Protesta popular en América Latina en los años de ajuste (pp. 211- 238). Caracas: Cátedra América Latina (Vicerrectorado Académico-UCV), Comisión de Estudios de Postgrado de la Facultad de Ciencias Económicas y Sociales (CEAP/FACES-UCV), Centro de Estudios del Desarrollo (CENDES-UCV), Nueva Sociedad. 
- $\quad$ López, S. y Hernández, R. (2001). Movimientos estudiantiles y crisis del sistema Político en Venezuela: 1987-1988. Espacio Abierto, 10 (4), 661-666.

- $\quad$ López, F. (2006). La crisis de los partidos y su impacto en el modelo sociopolítico venezolano. Revista Mañongó, XIV (26), 65-106.

- $\quad$ López-Alvez, F. (2003). La formación de estado y la democracia en América Latina. Bogotá: Editorial Norma.

- $\quad$ Lucena, T. (2003). Las reformas del sistema electoral venezolano y sus consecuencias políticas. Alceu, 3 (6), 245-265.

- Maingón, T., et al (2000). La batalla por una nueva constitución para Venezuela. Revista Mexicana de Sociología, 62 (4), 91-124.

- Mainwaring, S. (2002). Prefacio. En: S. Gutiérrez (Comp.), Degradación o Cambio. Evolución del sistema político colombiano (pp. 11-21). Bogotá: Grupo Editorial Norma.

- Mascareño, Q. (2007). El federalismo venezolano re-concentrado. Provincia (17) 11-22.

- Medina, M. (2001). El elegido presidente Chávez. Un nuevo Sistema político. Bogotá: Ediciones Aurora.

- Molina, G. (2004). Imágenes Colectivas y propuestas ideológicas del Estado y lo Público en Colombia a finales del siglo XX. Bogotá: Escuela Superior de Administración Pública.

- Molina, G. (2010). Democracia en Colombia y Poder Público ¿Es público o privado el estado en Colombia. Bogotá: Escuela Superior de Administración Pública, Facultad de Investigaciones.

- Molina, J. (2003a). Venezuela (notas introductorias al estudio de los partidos políticos venezolanos). En: M. Alcántara y F. Freidemberg (Cords.), Partidos políticos en América Latina. Países Andinos. México: Fondo de Cultura Económica-Instituto Federal Electoral.

- Molina, J. (2003b). Izquierda y estabilidad de la democracia en América Latina: la ideología de la revolución bolivariana y su repercusión sobre el proceso político en Venezuela y América Latina. América Latina hoy, 35, 169-198.

- Múnera, R. (1998). Rupturas y continuidades. Poder y movimiento popular en Colombia 1968-1988. Bogotá: IEPRI-Universidad Nacional de Colombia-CEREC. 
- Muñoz, l. y Pineda M. (2003). Nuevos partidos, nuevos liderazgos: Primero Justicia. Cuestiones políticas (30) 45-74.

- Murillo, M., Oliveros, V. y Vaishnav, M. (2010). Electoral revolution or democratic alternation? Latin American Research Review, 45 (3) 87-114.

- Pachón, M. (2010). Reforma Institucional en Colombia: El viacrucis entre el equilibrio de la gobernabilidad y la representación (1991-2006). En: M. Tanaka y F. Jácome (Eds.), Desafíos de la gobernabilidad democrática. Reformas político-institucionales y movimientos sociales en la región andina (pp. 47-78). Lima: Instituto de Estudios Peruanos.

- Pachón, M. (2002). El partido conservador y sus dinámicas políticas. En: S. Gutiérrez (Comp.), Degradación o cambio. Evolución del sistema político colombiano (pp. 79-131). Bogotá: Editorial Norma.

- $\quad$ Pizarro, L. (2008). Gigantes con pies de barro. Los partidos políticos en Colombia. En: S. Mainwaring, A. Bejarano y E. Pizarro (Eds.), La crisis de la representación democrática en los países andinos (pp. 133-162). Bogotá: Grupo Editorial Norma.

- Pizarro, L. (1990). La insurgencia armada en Colombia. Raíces y perspectivas. En: B. Leal, Al filo del Caos (pp. 411-443). Bogotá: Tercer Mundo Editores.

- Powel, J. (1970). Peasant Society and clientelist Politics. The American Political Sciencie Review, 64, (2) 411-425.

- Puerta, M. (2006). Aproximación a la crisis de la democracia y de la representación en Venezuela. Revista Mañongó, 14 (26).

- $\quad$ Rodríguez-Raga, J. (2002). ¿Cambiar todo para que nada cambie? Representación, sistema electoral y sistema de partido en Colombia: Capacidad de adaptación de las élites políticas a cambios en el entorno institucional. En: S. Gutiérrez (Comp.), Degradación o cambio. Evolución del sistema político colombiano (pp. 221-260). Bogotá: Editorial Norma.

- Romero, M. (2004). Democratización Política y Contra Reforma Paramilitar en Colombia. En: G. Sánchez y E. Lair (eds.), Violencias y Estrategias Colectivas en la Región Andina: Bolivia, Colombia, Ecuador, Perú y Venezuela (pp. 335-376). Bogotá: IFEA, IEPRI, Grupo Editorial Norma.

- Sabino, C. (1995). El sistema político venezolano. Estabilidad, crisis incertidumbre. Recuperado en noviembre de 2012 de: paginas.ufm.edu/sabino/word/.../sistema_politico_ venezolano.pdf. 
- $\quad$ Salamanca, L. (1994). Venezuela. La crisis del rentismo. Nueva sociedad, 131, 10-19.

- $\quad$ Salamanca, L. (1999). Protestas venezolanas en el segundo gobierno de Rafael Caldera: 1994-1997. En: M. Lopéz (ed.), Lucha popular, democracia, neoliberalismo: Protesta popular en América Latina en los años de ajuste (pp. 239-264). Caracas: Cátedra América Latina (Vicerrectorado Académico-UCV), Comisión de Estudios de Postgrado de la Facultad de Ciencias Económicas y Sociales (CEAP/FACES-UCV), Centro de Estudios del Desarrollo (CENDES-UCV), Nueva Sociedad.

- $\quad$ Salamanca, L. (2003). La sociedad civil venezolana en dos tiempos. 1972-2002. Revista Politei, 30 (30). Recuperado en noviembre de 2012 de: http://www2.bvs.org.ve/ scielo.php?script=sci_arttext\&pid=S0303-7572003000100008\&lng=es\&nrm =iso.

- $\quad$ Semana (2012, 27 de mayo - 3 de Junio). Álvaro Uribe, el jefe de la oposición. Edición digital. En. http://www.semana.com/nacion/alvaro-uribe-jefe-oposicion/177836-3.aspx

- $\quad$ Tanaka, M. (2008). De la crisis al derrumbe de los sistemas de partidos, y los dilemas de la representación democrática. Perú y Venezuela. En: S. Mainwaring, A. Bejarano, y E. Pizarro (Comp.), La crisis de la representación democrática en los países andinos (pp. 89-132). Bogotá: Grupo Editorial Norma.

- Valencia, R. (2005). Venezuela's Bolivarian Revolution. Who are the Chavistas? Latin American Perspectives, 32 (3), 79-97.

- Wills, O (2002). Inclusión política y exclusión cultural en Colombia: Pistas para comprender su relación. Análisis Político, 46. 